\title{
Thermospheric Dynamics During September 18-19, 1984 2. Validation of the NCAR Thermospheric General Circulation Model
}

\author{
G. Crowley, ${ }^{1,2}$ B. A. Emery, ${ }^{1}$ R. G. Roble, ${ }^{1}$ H. C. Carlson, Jr. ${ }^{3}$ J. E. Salah, ${ }^{4}$ V. B. Wickwar, ${ }^{5}$ \\ K. L. Miller, ${ }^{5}$ W. L. Oliver, ${ }^{4,6}$ R. G. Burnside, ${ }^{7}$ ANd F. A. Marcos $^{3}$
}

\begin{abstract}
The validation of complex nonlinear numerical models such as the National Center for Atmospheric Research thermospheric general circulation model (NCAR TGCM) requires a detailed comparison of model predictions with data. The Equinox Transition Study (ETS) of September 17-24, 1984, provided a unique opportunity to address the verification of the NCAR TGCM, since unusually large quantities of high-quality thermospheric and ionospheric data were obtained during an intensive observation interval. In a companion paper (paper 1) by Crowley et al. (this issue) a simulation of the September 18-19 ETS interval was described. Using a novel approach to modeling, the TGCM inputs were tuned where possible with guidance from data describing the appropriate input fields, and the arbitrary adjustment of input variables in order to obtain thermospheric predictions which match measurements was avoided. In the present paper the winds, temperatures, and densities predicted by the TGCM are compared with measurements from the ETS interval. In many respects, agreement between the predictions and observations is good. The quiet day observations contain a strong semidiurnal wind variation which is mainly due to upward propagating tides. The storm day wind behavior is significantly different and includes a surge of equatorward winds due to a global propagating disturbance associated with the storm onset. The density data confirm the existence of the newly discovered four-cell high-latitude density anomaly described in paper 1. A quantitative statistical comparison of the predicted and measured winds indicates that the equatorward winds in the model are weaker than the observed winds, particularly during storm times. This is consistent with predicted latitudinal temperature gradients and storm time density increases which are much smaller than the observed values. Soft particle precipitation or high-altitude plasma heating is invoked as a possible source of the additional high-latitude heating required by the model. A quiet day phase anomaly in the measured $F$ region winds which is not reproduced by the model suggests the occurrence of an important unmodeled interaction between upward propagating semidiumal tides and high-latitude effects. Wind data from altitudes below $100 \mathrm{~km}$ indicate shortcomings in the generic equinox solar minimum tidal specification used in the TGCM. The lack of appropriate data to specify input fields seriously impairs our ability to generate realistic global thermospheric simulations. The problem is particularly acute in the southern hemisphere. Furthermore, disturbances generated in the southern hemisphere simulation propagate northward and degrade the northern hemisphere predictions. Thus, if the thermosphere in the northern hemisphere is ever to be fully understood, the southern hemisphere needs to be observed and simulated more accurately. Several improvements are suggested for future realistic time-dependent simulations of specific intervals.
\end{abstract}

\section{INTRODUCTION}

The validity of complex numerical models, such as the National Center for Atmospheric Research (NCAR) thermospheric general circulation model (TGCM), must be assessed so that they can be exploited for further geophysical studies and for practical applications, such as "space weather" prediction. Validation of thermospheric models is particularly difficult since thermospheric science is data-poor, especially when compared with tropospheric studies. This is partly due to the difficulty of measuring basic parameters

\footnotetext{
${ }^{1}$ High Altitude Observatory, National Center for Atmospheric Research, Boulder, Colorado.

${ }^{2}$ Now at Center for Atmospheric Research, University of Lowell, Lowell, Massachusetts.

${ }^{3}$ Air Force Geophysics Laboratory, Hanscom Air Force Base, Bedford, Massachusetts.

${ }^{4}$ Haystack Observatory, Massachusetts Institute of Technology, Westford.

${ }^{5}$ Center for Atmospheric and Space Sciences, Utah State University, Logan.

${ }^{6}$ Now at Department of Electrical, Computer and Systems Engineering, Boston University, Boston, Massachusetts.

${ }^{7}$ Arecibo Observatory, Arecibo, Puerto Rico.

Copyright 1989 by the American Geophysical Union.

Paper number 89JA01550.

0148-0227/89/89JA-01550\$05.00
}

such as density and temperature at thermospheric heights. The Equinox Transition Study (ETS) of September 17-24, 1984 , provided a unique opportunity to address the verification of the NCAR TGCM, since unusually large quantities of high-quality thermospheric and ionospheric data were obtained during an intensive observation interval [Carlson and Crowley, this issue].

One of the main problems for obtaining realistic predictions of global thermospheric dynamics using TGCMs is the specification of the three-dimensional, time-dependent forcing fields for any given day. There are enough adjustable parameters in the specification of TGCM forcing fields that the simulation of thermospheric effects at a single station is relatively easy. However, little effort has so far been made to reduce the number of free parameters (by reference to large quantities of data) and then to accurately simulate thermospheric conditions at many locations simultaneously.

In a companion paper by Crowley et al. [this issue], hereinafter called paper 1 , the thermospheric response to the ETS magnetic storm of September 19, 1984, was simulated using the NCAR TGCM. The inputs for this simulation were "state of the art," and the number of free parameters was reduced to a minimum. The arbitrary adjustment of input variables in order to obtain thermospheric predictions which match measurements was explicitly avoided.

The location and size of the auroral oval and the energies 
of precipitating particles in the model were tuned by reference to satellite data collected during the ETS period. The resulting auroral electron density enhancements were added to the densities obtained from the international reference ionosphere (IRI) [Bilitza, 1986], and the total electron density was used to calculate ion drag, momentum forcing, and Joule heating terms at each TGCM time step. The $\mathrm{O}-\mathrm{O}^{+}$ collision cross section is another important parameter in determining the ion drag. Recent work by Burnside et al. [1987] suggests that the $\mathrm{O}-\mathrm{O}^{+}$collision cross section of Schunk and Walker [1973] is too small, and its value was therefore increased by a factor of 1.5 in the present simulation. The convection patterns [Knipp et al., this issue] for the ETS interval were derived from the assimilative mapping of ionospheric electrodynamics (AMIE) technique of Richmond and Kamide [1988], which provides a best fit potential pattern (in the least squares sense) to a variety of ionospheric data. Paper 1 also emphasized the importance of upward propagating semidiurnal tides for thermospheric dynamics. These tides were specified at the TGCM lower boundary using the results of Fesen et al. [1986] for equinox solar minimum conditions.

In the present paper the accuracy of the TGCM predictions is assessed by comparison with observations from many locations. Meridional neutral winds are the main geophysical parameter used in assessing the validity of the TGCM simulations for a number of reasons: they may be inferred by a variety of measurement techniques, they are available at all times of day from many locations, they are very sensitive to changes of high latitude and tidal forcing, and they, in turn, play a major part in determining temperature, density, and composition changes on a global scale. For the ETS interval, meridional neutral wind estimates were obtained from the European Incoherent Scatter (EISCAT), Sondre Stromfjord, Millstone Hill, and Arecibo incoherent scatter radars in addition to a network of 12 ionosondes in the northern hemisphere (Figure 1). For the first time, the differences between the predicted and measured winds are quantitatively assessed. Times and locations where the differences are likely to be exceptionally small or large are identified.

In addition to the meridional winds, the predicted neutral temperatures and densities are also compared with data. The model accurately reproduces many features of the ETS data and may therefore be considered realistic. Analysis of the model thus permits various observed phenomena to be investigated and leads to an improved understanding of the thermosphere. Discrepancies between the predictions and observations yield additional insights. Areas requiring further research are identified, and several improvements are suggested for future simulations.

\section{Results}

\subsection{Meridional Neutral Winds}

The neutral wind velocity component in the magnetic plane may be determined from incoherent scatter radar measurements of $F$ region ion drift [e.g., Vasseur, 1969; Harper, 1973; Salah and Holt, 1974; Oliver and Salah, 1988]. The technique has been widely applied at various radar locations. It involves the determination of the ion velocity parallel to the magnetic field at a particular altitude

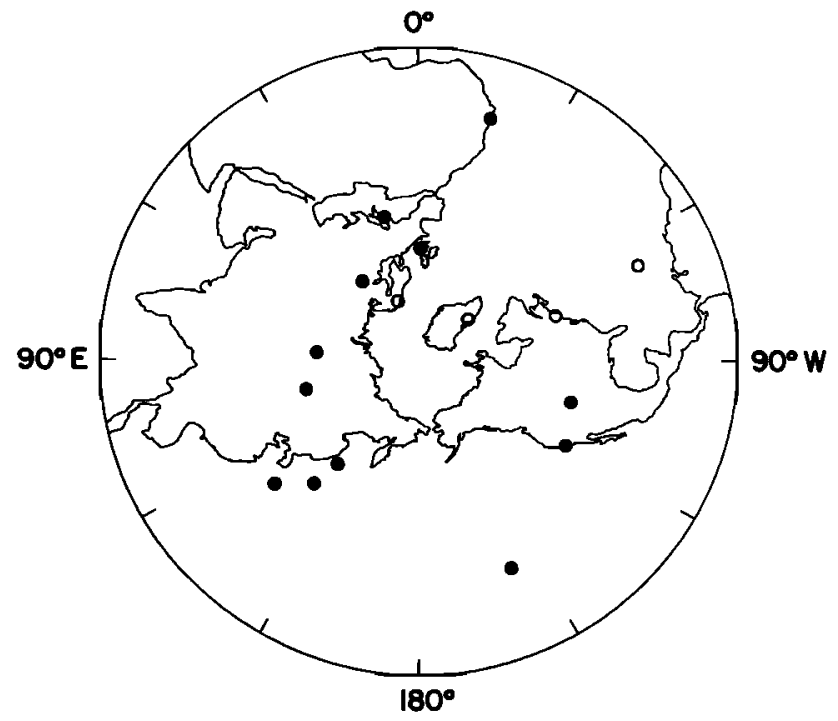

Fig. 1. Location of 12 ionosondes (solid circles) and four incoherent scatter radars (open circles) from which meridional neutral winds were derived during the ETS.

in the $F$ region, and subtraction of the diffusion velocity component. Ignoring the normally small vertical wind component, the projection of the residual velocity onto the horizontal plane yields an estimate of the neutral wind.

Computation of the ion diffusion velocity involves a knowledge of the neutral atmospheric temperature and composition, in addition to a value for the $\mathrm{O}-\mathrm{O}^{+}$collision cross section [e.g., Burnside et al., 1988]. The neutral parameters are normally obtained from a model such as MSIS [Hedin, 1983, 1987], which may be significantly different from the conditions which actually existed on the date of interest. The $\mathrm{O}-\mathrm{O}^{+}$collision cross section is currently a subject of debate. Burnside et al. [1987] have suggested that the values derived from the Schunk and Walker [1973] formula should be increased by a factor of $1.7\left[{ }_{-0.3}^{+0.7}\right]$.

Ionosonde data have also been used to deduce the meridional neutral wind component. Miller et al. [1986] describe a method for obtaining the wind from measurements of the height of the maximum electron concentration in the $F_{2}$ region $\left(h_{\max }\right)$. The method involves the use of an ionospheric model to develop a relationship between the meridional wind speed and $h_{\max }$. The meridional wind is then derived by a comparison of the modeled and measured layer heights. Miller et al. [1987] estimate that statistical errors in the ionosonde data analysis generate wind uncertainties of $30 \%$. This value was used to represent error bars in the present paper, although more realistic error bars might be as large as $75 \mathrm{~m} \mathrm{~s}^{-1}$ when some of the assumptions involved in the analysis are considered. The effects of vertical winds on $h_{\max }$ are neglected, as in the radar analysis. The derivation of neutral winds by this technique also neglects the effects of electric fields, although Miller et al. [1987] found that this does not usually lead to significant errors during quiet conditions. The $h_{\max }$ analysis also involves many of the same assumptions as the radar analysis in terms of neutral atmospheric parameters and the $\mathrm{O}-\mathrm{O}^{+}$collision cross section. The assumptions and uncertainties involved in obtaining meridional neutral winds from both incoherent scatter 
radar ion drift data and $h_{\max }$ data are discussed in detail by Buonsanto et al. [this issue].

Figure 2 illustrates the meridional neutral winds (geomagnetic north positive) as a function of universal time measured (solid line) at five locations during September 18, a quiet day, and September 19, a disturbed day. The TGCM predictions (dashed line) are also plotted for comparison. Millstone Hill and Arecibo are incoherent scatter radar sites in the American sector, while Rome, Tomsk, and Tokyo are ionosonde sites in the European, Russian, and Japanese sectors, respectively (Table 1). Rome and Millstone Hill have similar geographic latitudes, but the magnetic latitude of Rome is about $15^{\circ}$ less than that at Millstone Hill. Arecibo and Tokyo have the same magnetic latitude, but the geographic latitude of Arecibo is about $20^{\circ}$ less than that of Tokyo. Note that the uncertainties in the winds derived from ionosonde data are generally comparable with those associated with incoherent scatter radar data, and the predictions for each station fall within the measurement error bars at various times, especially on the quiet day.

The quiet day measurements display a strong diurnal variation, with a tendency toward poleward daytime winds. Table 1 indicates the universal and local times for which quiet time poleward and equatorward winds were observed for each station. The duration of the poleward winds is shorter for higher magnetic latitudes. Thus Millstone Hill observed poleward winds for only 9 hours, between 05 and $13 \mathrm{LT}$ on the quiet day, in contrast to the other stations where winds were poleward for up to 18 hours. The equatorward winds of the quiet day reached magnitudes of $100-150 \mathrm{~m} \mathrm{~s}^{-1}$ at each station.

The large poleward winds obtained from the Rome and Tokyo ionosonde data in the evening hours (Figures $2 c$ and $2 e$ ) were unexpected, and their origin appears to be tidal. The data do not appear to be erroneous; however, the analysis neglected electric field effects which may have contributed to the apparent poleward winds.

The observed strong diurnal wind variation is reasonably well modeled by the TGCM. An additional feature of the predicted winds is the strong semidiurnal variation which was discussed in paper 1. Maxima in the model poleward winds at about 06 and $18 \mathrm{LT}$ are generated, in part, by the upward propagating semidiurnal tides. As a result of these tides, the model predicts poleward winds during about 16 hours for each site. This agrees well with the observed variation listed in Table 1 for Arecibo, Tokyo, Rome, and Tomsk, although the model wind variation tends to be phase shifted to earlier times (0-4 hours) with respect to the data. For Millstone Hill the predicted winds contain a strong semidiurnal component which contrasts with the observed wind variation. The predicted winds thus blow poleward for 16 hours, compared with the observed 9 hours which is typical of summertime behavior for this location.

On the active day the measured winds are considerably different from their quiet day values. At Millstone Hill the winds remained equatorward during the whole day, diverging from the quiet day wind pattern as early as 05 UT. This behavior suggests that some form of disturbance occurred to the north of Millstone Hill before the main storm commenced at 10 UT. Sondre Stromfjord (not shown) is the only other site containing similar early divergence from quiet day values, indicating that the "precursor" event was localized in the American sector.
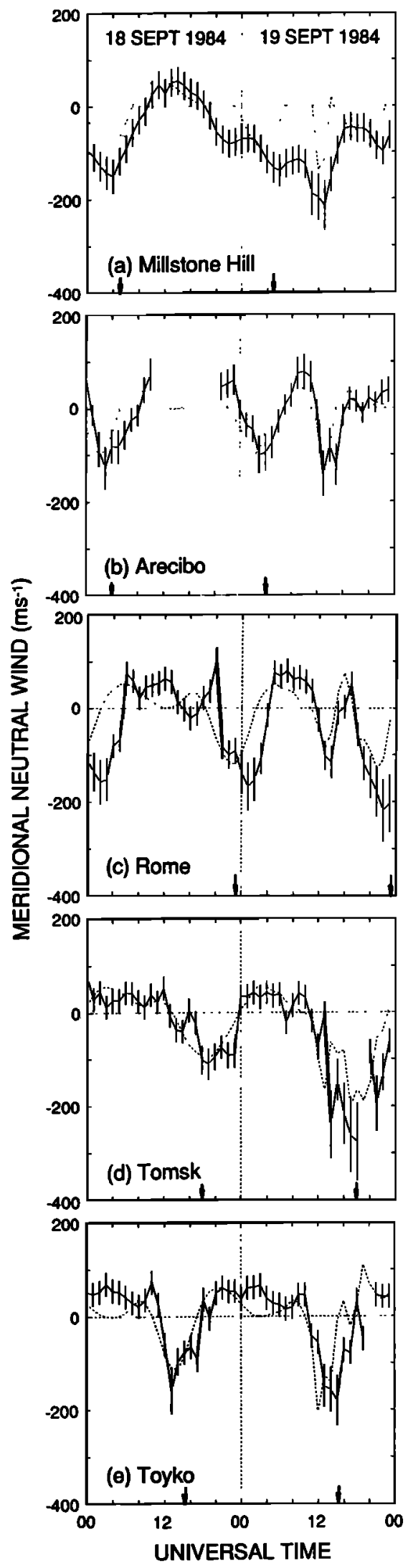

Fig. 2. Meridional neutral winds close to $300 \mathrm{~km}$ measured (solid) and predicted (dashed) for (a) Millstone Hill, (b) Arecibo, (c) Rome, $(d)$ Tomsk, and (e) Tokyo. Negative values indicate equatorward winds; units are meters per second. Note that the radar data (Millstone Hill and Arecibo) were averaged over $50 \mathrm{~km}$ in altitude and smoothed with a 1-hour running mean before interpolating to hourly values. Vertical arrows indicate local midnight. 
TABLE 1. Intervals During Which Measured Winds Plotted in Figure 2 Are Poleward or Equatorward

\begin{tabular}{|c|c|c|c|c|c|c|c|c|c|}
\hline & \multicolumn{2}{|c|}{$\begin{array}{l}\text { Geographic } \\
\text { Coordinates }\end{array}$} & \multicolumn{2}{|c|}{ Magnetic Coordinates } & \multirow[b]{2}{*}{ Declination } & \multicolumn{2}{|c|}{$\begin{array}{l}\text { Quiet Time Poleward } \\
\text { Winds }\end{array}$} & \multicolumn{2}{|c|}{$\begin{array}{l}\text { Quiet Time Equatorward } \\
\text { Winds }\end{array}$} \\
\hline & Latitude & Longitude & Latitude & Longitude & & UT & $\mathbf{L T}$ & UT & LT \\
\hline Millstone & 42.6 & -71.5 & 53.9 & -1.4 & -14.0 & $10-18$ & $05-13$ & $19-09$ & 14-04 \\
\hline Arecibo & 18.3 & -66.7 & 29.8 & 3.9 & -8.0 & $09-24$ & 05-20 & $01-08$ & $21-04$ \\
\hline Tokyo & 36.4 & 140.6 & 28.5 & -150.7 & -7.0 & $18-11$ & $03-20$ & $12-17$ & $21-02$ \\
\hline Rome & 41.9 & 12.52 & 36.05 & 86.5 & -3.0 & 06-20 & $07-21$ & $21-05$ & $22-06$ \\
\hline Tomsk & 56.5 & 84.9 & 46.0 & 160.6 & 12.0 & $00-13$ & $04-17$ & $14-23$ & $18-03$ \\
\hline
\end{tabular}

The most outstanding feature of the winds measured on September 19 is the surge of equatorward winds between about 10 and 17 UT. This surge was present in every data set and was associated with a large disturbance which propagated equatorward from the auroral zone. The surge will be discussed more fully in a later paper, but we briefly mention some of the surge features here, in comparing the measured and predicted winds.

Winds derived from ionosonde data were available only hourly. The radar data were therefore averaged and interpolated to hourly values and compared with hourly TGCM predictions. The magnitude of the observed wind surge in Figure 2 is $100-200 \mathrm{~m} \mathrm{~s}^{-1}$, with peak velocities occurring later at lower latitudes. Analysis of the unaveraged data (not shown) reveals that the disturbance has two maxima, both of which reached Arecibo 1 hour after passing the location of Millstone Hill. This corresponds to a propagation speed of $650-700 \mathrm{~m} \mathrm{~s}^{-1}$. At the present time, the interpretation of the two maxima in the data is unclear. The two peaks may be consecutive cycles of the same wave, or they may be due to entirely independent waves. For the purposes of the present paper the distinction is relatively unimportant, since the TGCM reproduces the first maximum very well, at all locations, but the second wind maximum is not predicted. The predicted surge therefore appears to last for a shorter time than the observed event.

Figure 3 is a geographic polar plot depicting the progression of the peak of the disturbance from high to low latitudes between 12 and 14 UT on September 19. The TGCM predictions are denoted by solid lines, while the maxima deduced from the wind data are given by dashed lines. The predicted phase fronts are distorted because of different propagation speeds on the dayside and nightside. Part of the distortion probably arises from propagation through the strong antisunward polar cap wind system. The source of the disturbance in the TGCM is the postmidnight sector, and this is the sector in which the wave amplitudes are largest and the phase progression is clearest. The amplitude of the disturbance is much smaller on the opposite side of the polar cap in the afternoon sector, and the shape of the phase fronts cannot be traced with certainty. Figure $2 c$ indicates that the peak of the predicted surge at Rome occurred about 13 UT and had an amplitude of only $75 \mathrm{~m} \mathrm{~s}^{-1}$. The situation is further confused in this sector because the phase fronts appear to be discontinuous. At $90^{\circ} \mathrm{E}$ the disturbance is present simultaneously at two different latitudes, presumably because the energy took different paths.

Because of the incomplete data set and 1-hour time resolution, the sketching of measured wave fronts in Figure 3 is incomplete and somewhat ambiguous; however, the model appears to have predicted many features of the observed disturbance with remarkable accuracy. Globally, the distorted wave fronts are reproduced, with a discontinuity in the European sector. The speed of propagation is virtually identical with the measured speed, and the timing of the event is correct to within $15 \mathrm{~min}$.

The storm time wind variation in the Japanese and Russian sectors is exceptionally complex, as illustrated by Figures $2 e$ and $2 d$, for Tokyo and Tomsk, respectively. At Tokyo the propagating disturbance is superposed on the normal midnight surge, such that the latter appears to be increased in amplitude. However, the model winds quickly abate because the second part of the surge was not generated in the TGCM and also because of the arrival of a disturbance generated in the southern hemisphere. We surmise that the high-latitude forcing in this sector of the southern hemisphere may be too strong in the model.

The winds observed at Tomsk were enhanced throughout the afternoon and evening from 12 to 23 UT beginning with the storm-associated surge which occurred about 12 UT (18 LT). In the model the surge is predicted at 12-13 UT; then the winds return to quiet time values before further strong equatorward winds are predicted from 16 to 21 UT. The

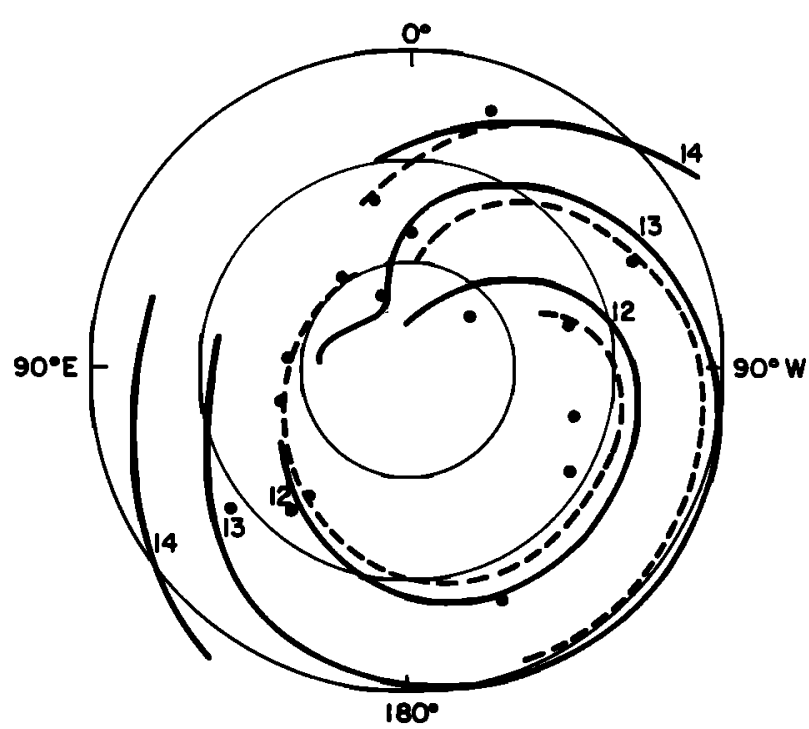

Fig. 3. Global propagation of disturbance between 12 and 14 UT on September 19 (day 263). Latitude contours are $0^{\circ}, 30^{\circ}$, and $60^{\circ} \mathrm{N}$. Solid curves represent the locus of maximum equatorward winds and temperature increases predicted by the TGCM. Dashed lines illustrate wind maxima deduced from data. Solid circles indicate locations from which wind data were available. 
discrepancy between the observed and predicted winds from 14 to 16 UT is again due to both the lack of a second "cycle" in the predicted storm surge and the disturbance which in the model propagates from the southern hemisphere. A similar picture is obtained throughout this longitude sector.

It is interesting to note that the generation of large disturbances in the southern hemisphere of the TGCM occurred near local midnight for both the Japanese and European sectors. A second disturbance launched at 18 UT in the southern hemisphere reached Rome at 22-23 UT, causing a rapid abatement of the model winds, while the data indicate an unusually strong equatorward wind at that time (Figure 2c). The southern hemisphere high-latitude forcing in the midnight local time sector may be generally too strong in the TGCM.

Exact replication of measured thermospheric properties by the TGCM should not be expected, since both the data analysis techniques and the model are imperfect. The verification of thermospheric models and the intercomparison of various simulations require a quantitative analysis of the differences between the measured and predicted properties, or between model predictions. We therefore present a brief statistical analysis of the differences between the measured winds of the ETS period and those predicted by the TGCM simulation. This analysis has been performed for the combined 48-hour data set, applying equal weighting to data from the four incoherent scatter radars and the 12 ionosondes (Figure 1). In general, the rms and mean differences will be discussed, instead of the standard deviation. This is because we are interested in how well the TGCM could predict thermospheric properties in a forecasting situation. Computation of the standard deviation requires a subtraction of the mean difference, which would not be known a priori.

Figure 4 indicates the distribution of the differences between measured and predicted winds for day 262 and day 263 with their respective mean and rms deviations. The differences range from $+250 \mathrm{~m} \mathrm{~s}^{-1}$ to $-350 \mathrm{~m} \mathrm{~s}^{-1}$, but both the mean and rms deviations are smaller on day 262 (September 18) than on day 263 (September 19). For the active day a mean deviation of $-27 \mathrm{~m} \mathrm{~s}^{-1}$ indicates that the observed equatorward winds are consistently stronger than those produced by the model.

The distribution of differences has been broken down further into smaller sets, in order to identify under what circumstances they are most significant. The rms difference has different properties on days 262 and 263 (Figure 5). On the quiet day (262) it is approximately constant with latitude, while for the active day (263) the rms difference increases with latitude. These variations are particularly clear when plotted in terms of geographic latitude. The mean difference (not shown) becomes more negative with increasing latitude on both days and is on average $30 \mathrm{~m} \mathrm{~s}^{-1}$ more negative on day 263 at all latitudes. The same result is obtained for both geographic and geomagnetic latitudes.

The rms, mean, and standard deviations of the differences are plotted as functions of universal time in Figure 6. The number of stations available for each UT is also presented (Figure $6 d$ ) and varies from 10 to 15 . The rms deviation increases from about $60 \mathrm{~m} \mathrm{~s}^{-1}$ on the quiet day to more than $100 \mathrm{~m} \mathrm{~s}^{-1}$ after the storm on September 19. The rms deviation comprises the mean and the standard deviations, both of which also increase over 48 hours. The most dramatic increase is in the mean deviation, which is approxi-

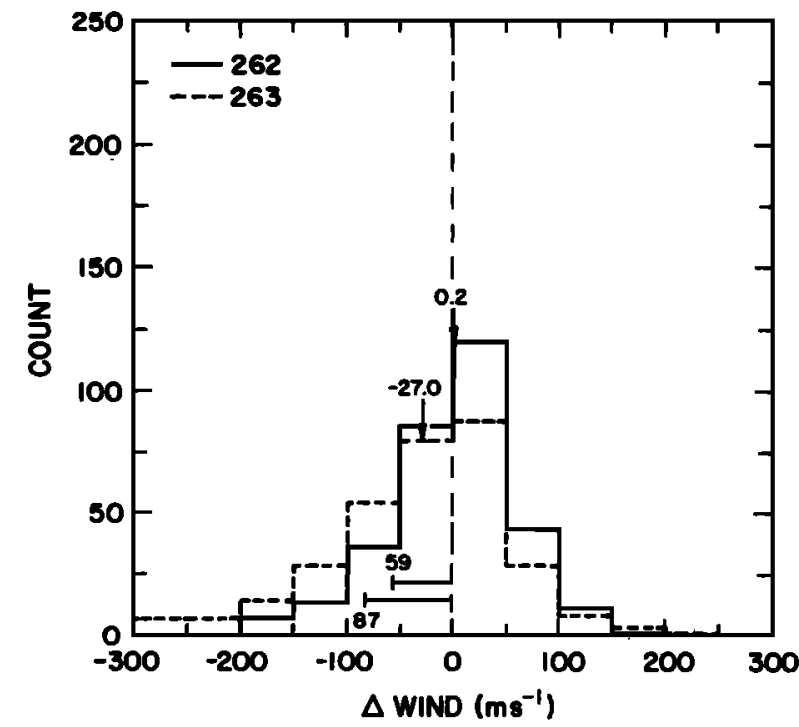

Fig. 4. Distribution of differences between measured and predicted meridional neutral wind speeds. The mean $\left(0.2 \mathrm{~m} \mathrm{~s}^{-1}\right)$ and rms $\left(59 \mathrm{~m} \mathrm{~s}^{-1}\right)$ deviations for the quiet day (262) are smaller than those for the active day, which were $-27 \mathrm{~m} \mathrm{~s}^{-1}$ and $87 \mathrm{~m} \mathrm{~s}^{-1}$, respectively.

mately zero before the storm onset and during the equatorward surge (10-13 UT, day 263) but then rapidly drops to almost $-100 \mathrm{~m} \mathrm{~s}^{-1}$ before slowly recovering to $-50 \mathrm{~m} \mathrm{~s}^{-1}$. These negative values indicate that the measured winds

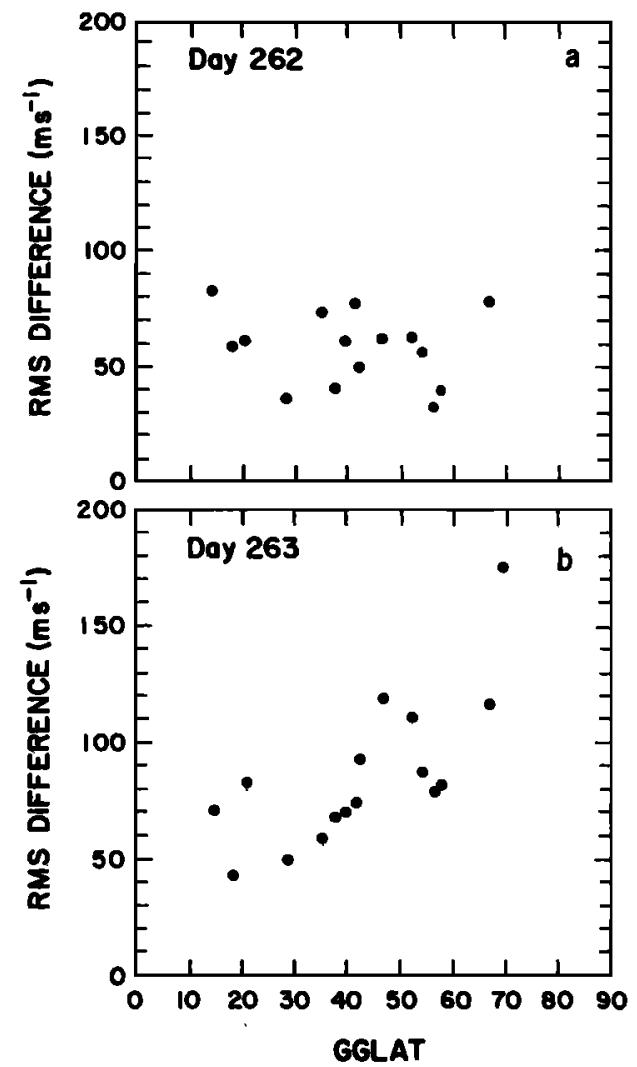

Fig. 5. Latitudinal variation for rms deviation of the predicted winds from the measured winds. (a) Quiet day (262). (b) Active day (263). 

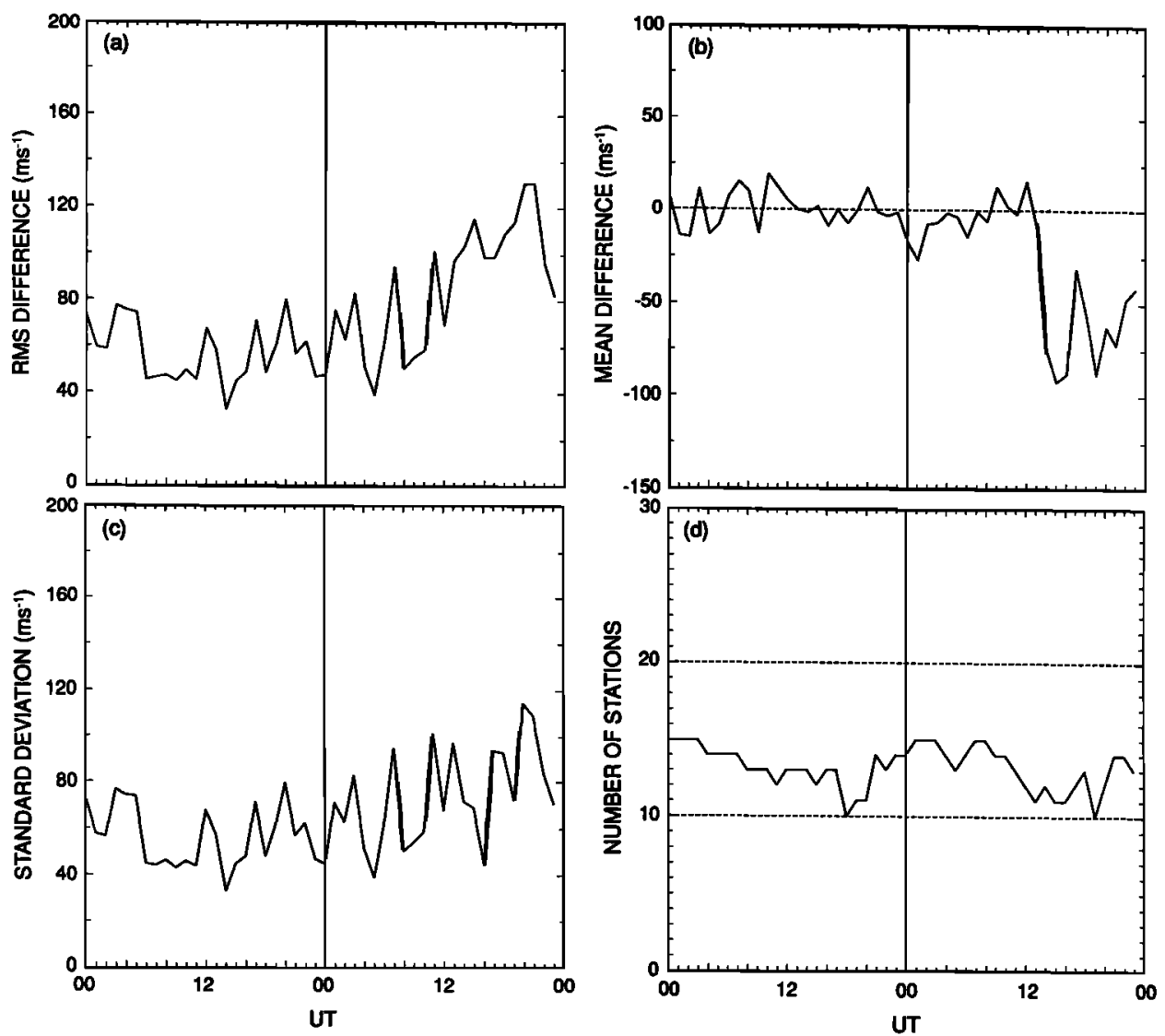

Fig. 6. Statistical deviations of predicted winds from measured winds for 48 hours during September 18-19, 1984: (a) rms difference, $(b)$ mean difference, $(c)$ standard deviation, and $(d)$ number of stations contributing to statistics.

remained strongly equatorwards after the storm for longer than the TGCM predicts.

Dividing the stations into three approximately equal groups at high, middle, and low latitudes, and considering each day separately, the local time variation of the differences is examined in Figure 7. For the quiet day (Figure 7a) the mean difference generally lies between $\pm 50 \mathrm{~m} \mathrm{~s}^{-1}$ at all latitudes, with a tendency to be largest for middle and high latitudes at night. For low latitudes the mean difference tends to maximize around dawn and dusk and may be associated with the phasing of the tides in the TGCM, as discussed for individual stations above.

On the active day (Figure $7 b$ ) the differences are smallest at low latitudes and largest at high latitudes. The same distinct diurnal variation of the mean differences occurs at all three latitude ranges; the smallest differences occur during
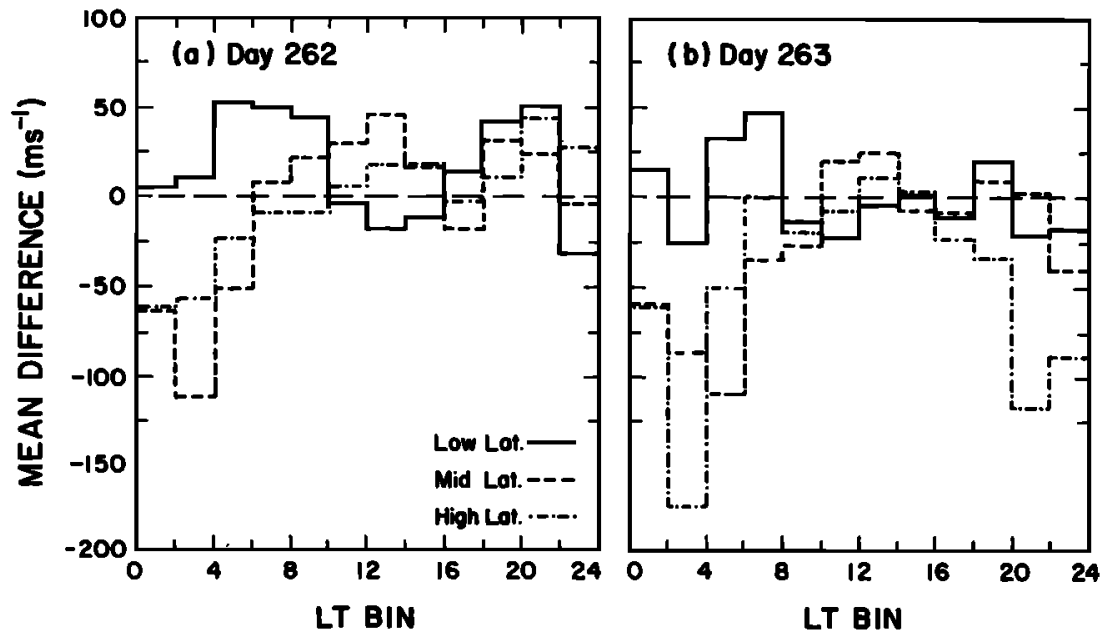

Fig. 7. Local time variation of mean difference between predicted and measured winds. Low, middle, and high geographic latitudes were considered separately. (a) Quiet day (262). (b) Active day (263). Negative values indicate that the measured winds blew more strongly equatorward than the predicted winds. 


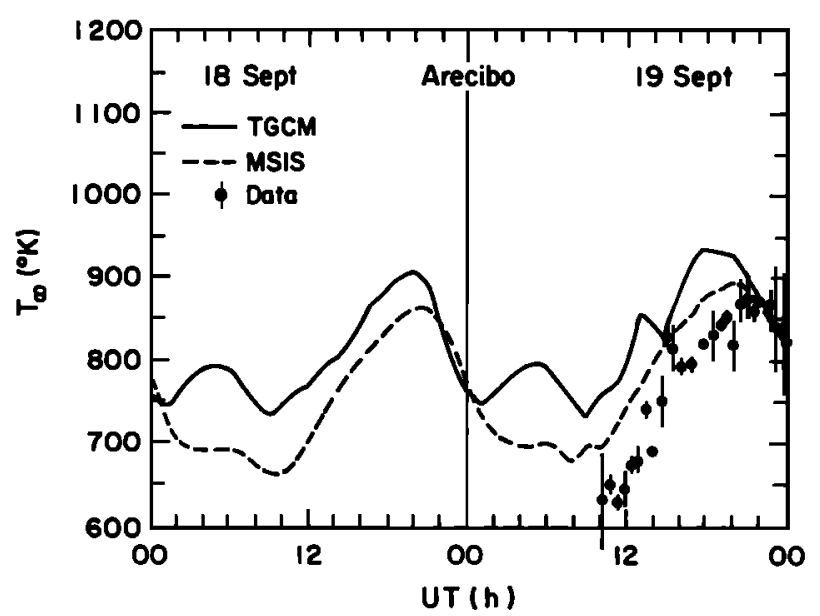

Fig. 8. Exospheric temperature variation predicted and measured for Arecibo during September 18-19, 1984.

the daytime between 08 and $18 \mathrm{LT}$. A similar conclusion is reached for the rms and standard deviations (not shown).

\subsection{Neutral Temperatures}

The determination of exospheric and neutral temperatures from incoherent scatter radar measurements has recently been described in detail for Arecibo [Burnside et al., 1988] and for Millstone Hill [Hagan and Salah, 1988; Oliver and Salah, 1988]. In this section the exospheric temperature estimates from the Arecibo and Millstone Hill ETS data are compared with those predicted by the TGCM and MSIS-86 models.

Figure 8 illustrates the exospheric temperature variations predicted for September 18-19, 1984, at Arecibo by the MSIS-86 model and the TGCM. Both models predict moderate temperature increases of about $50 \mathrm{~K}$ over quiet time values following the storm onset at 10 UT on September 19. In general, the TGCM predictions exceed the MSIS temperatures by about $50 \mathrm{~K}$. Incoherent scatter radar data were available from 10 UT on September 19 and are superposed on Figure 8. The measured temperatures are about $50 \mathrm{~K}$ less than those predicted by the MSIS model, and almost $100 \mathrm{~K}$ less than those of the TGCM except for the last few hours of September 19. The data also contain two short-lived temperature enhancements at about 13 UT and 15 UT on September 19 , which are associated with the equatorward wind surge described above. As with the winds, the TGCM predicted the first peak (13 UT), but not the second (15 UT).

A similar discrepancy between the MSIS model and measured temperatures was reported both by Hagan and Salah [1988] and by Burnside et al. [1988] for solar minimum conditions. Burnside et al. [1988] attribute the discrepancy to a problem with the MSIS model. Analysis of the Arecibo radar data incorporated in the MSIS model neglected $\mathrm{H}^{+}$ ions for altitudes around $400 \mathrm{~km}$, since they were not originally thought to be significant at solar minimum. This gave rise to MSIS temperatures systematically too hot by 50 $K$. During the ETS interval, solar $F_{107}$ fluxes were comparable with those of solar minimum conditions (about 70), and significant concentrations of $\mathrm{H}^{+}$were observed at Arecibo [Tepley and Kerr, 1987]. Temperatures deduced from the Arecibo radar data were not corrected for $\mathrm{H}^{+}$and will

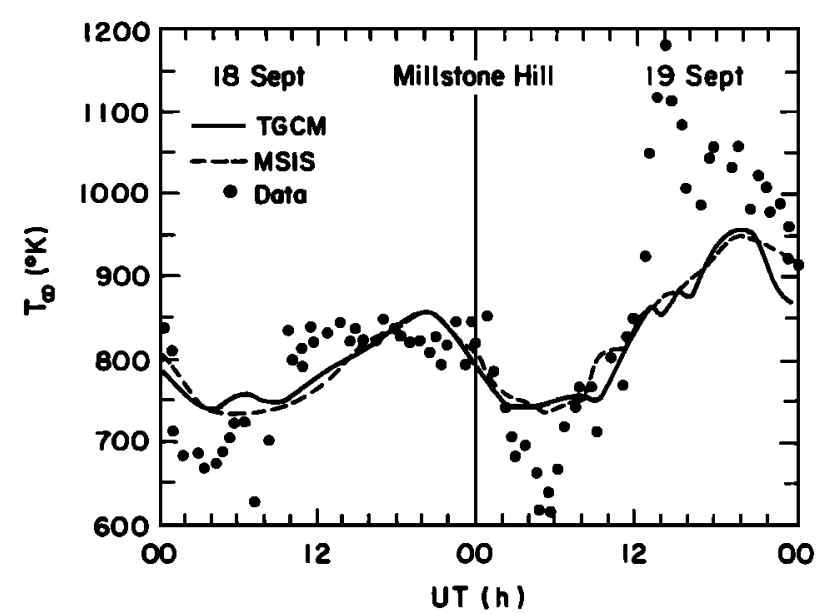

Fig. 9. Exospheric temperature variation predicted and measured for Millstone Hill during September 18-19, 1984.

therefore be too high by about $50 \mathrm{~K}$. Note that the discrepancy between the MSIS/TGCM predictions and measured temperature would have been even larger if $\mathrm{H}^{+}$ions had been taken into account in the ETS data analysis.

Figure 9 illustrates the corresponding temperature variations for Millstone Hill. The TGCM predictions essentially track MSIS, except after 21 UT on September 19 when the TGCM recovers more rapidly from storm effects than MSIS. For both nights the quiet time model temperatures are $100 \mathrm{~K}$ hotter than the measured temperatures. Conversely, the models underestimate the observed storm effects by up to $350 \mathrm{~K}$, subject to the uncertainties discussed below. A similar discrepancy was noted by Hagan [1988] for a winter solstice solar minimum study.

The validity of storm time exospheric temperature estimates from radar observations has been discussed in detail by Hagan [1988], who suggests that overestimates may result from contamination of the ion temperatures by ionfrictional heating, particle bombardment, and molecular ions. In the present case, none of these effects is strong enough to generate the exospheric temperature enhancements plotted in Figure 9. Both the frictional heating and molecular ion contamination would require electric fields of about $50 \mathrm{mV} \mathrm{m}^{-1}$ and must be discounted because the electric fields measured at Millstone Hill were too small $(<20$ $\mathrm{mV} \mathrm{m}^{-1}$ ). Similarly, although there was evidence of particle precipitation in the vicinity of Millstone Hill during the ETS interval, it was not sufficiently intense to generate the observed exospheric temperature increase. These increases will be discussed in detail in a separate paper and are due to two causes. The background temperature increases of 100 $200 \mathrm{~K}$ between 12 and $24 \mathrm{UT}$ are due to the transport of hot air from the auroral zone into the Millstone Hill radar field of view. An additional enhancement at 14 UT is caused by compression associated with the second peak of the propagating wind surge which was not predicted by the TGCM.

The temperature gradient between Millstone Hill and Arecibo is of interest because it affects the meridional neutral wind component. For the quiet day the two models predict temperature differences of $\pm 75 \mathrm{~K}$, depending on local time. Both models predict that on the active day the Millstone Hill temperatures increase more than the Arecibo 
temperatures, resulting in a temperature gradient which tends to drive stronger equatorward winds. The MSIS model predicts that the Millstone Hill temperature remains $50 \mathrm{~K}$ higher than the Arecibo temperature, while the TGCM predicts a smaller difference. In contrast, the measured temperature difference between Arecibo and Millstone Hill is typically $200 \mathrm{~K}$, reaches a maximum of $450 \mathrm{~K}$, and falls to $75 \mathrm{~K}$ by $24 \mathrm{UT}$. In addition, the Arecibo temperatures are probably overestimated by $\sim 50 \mathrm{~K}$ owing to the neglect of $\mathrm{H}^{+}$, as mentioned above, so the true temperature gradient may be even larger. The radar data from September 19 are thus consistent with the models in the sense that the Millstone Hill temperatures increased more than the Arecibo temperatures; however, the magnitude of the observed increase and corresponding temperature gradient is much greater than the models predict. The temperature data are thus qualitatively consistent with stronger equatorward winds than predicted by the models, especially during the storm period.

Rishbeth [1972] provides formulae to estimate the neutral winds that would result from a given horizontal $F$ region temperature gradient. A simplistic calculation indicates that the $75-\mathrm{K}$ to $400-\mathrm{K}$ temperature difference between Millstone Hill and Arecibo would drive meridional neutral winds ranging from $150 \mathrm{~m} \mathrm{~s}^{-1}$ to $820 \mathrm{~m} \mathrm{~s}^{-1}$. It is therefore possible to account quantitatively for the lack of equatorward winds in the TGCM as compared with the data.

\subsection{Neutral Density}

During the ETS interval the Air Force Geophysics Laboratory (AFGL) S85-1 satellite accelerometer experiment [Marcos and Forbes, 1985] measured total atmospheric density in an almost circular orbit at altitudes between 197 and $201 \mathrm{~km}$. Examination of the TGCM predictions for this altitude region has led to the discovery of a new high-latitude density anomaly as described briefly in paper 1 . The morphology of the anomaly and its causative mechanisms will be discussed in detail in a later paper.

Several aspects of the satellite data merit inclusion in the TGCM verification process. Figure $10 a$ illustrates the measured density variation with latitude in the noon sector at about $1420 \mathrm{UT}$. The typical quiet day variation is given by a dashed line for comparison. By 1420 UT the density at 200 $\mathrm{km}$ has increased by $30-50 \%$ at all latitudes because of the storm time energy input and resultant thermospheric expansion. Two high-density regions were observed at $65^{\circ} \mathrm{N}$ and $40^{\circ} \mathrm{N}$.

To set these observations in context, the TGCM density predictions for $200 \mathrm{~km}$ at $14 \mathrm{UT}$ are presented as Figure $10 b$. In this case, the dominant polar cap features are a highdensity region in the noon sector and an intense low-density region in the dawn sector. The satellite path is traced as a heavy line in the noon sector and indicates that the high density observed at $65^{\circ} \mathrm{N}$ is part of the high-latitude density anomaly noted above, while the density peak centered at $40^{\circ} \mathrm{N}$ is due to an equatorward propagating disturbance. When the altitude variation of the satellite is taken into account, the amplitudes of the observed and predicted density perturbations are also very similar.

Figure 11 compares the typical variation of observed prestorm densities with those from the late storm phase about 17-21 UT. The densities measured at $200 \mathrm{~km}$ during
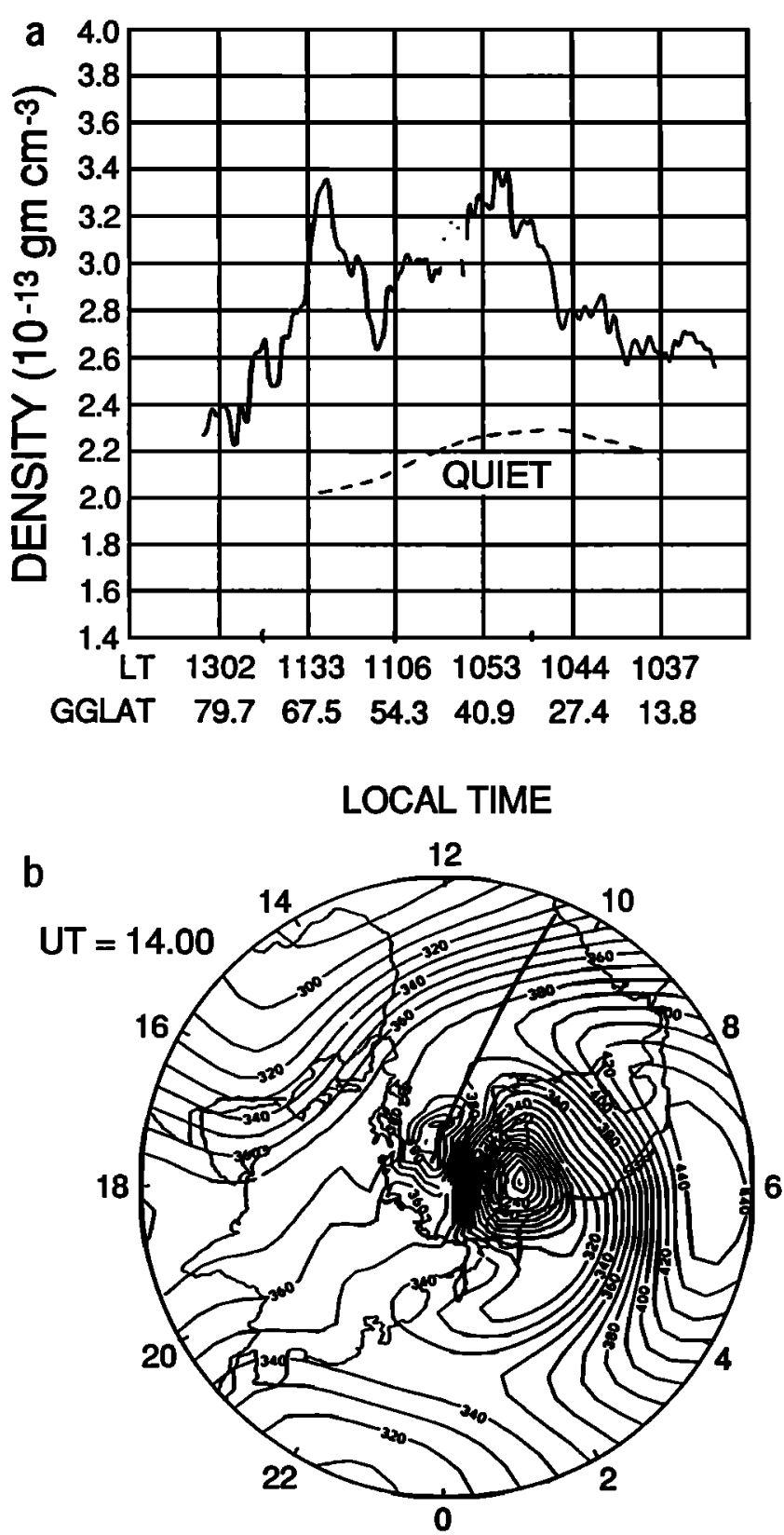

Fig. 10. (a) Latitudinal variation of neutral density measured by the S85-1 satellite for altitudes close to $200 \mathrm{~km}$ about 1420 UT on September 19, 1984. The typical corresponding quiet day variation is also shown for comparison (dashed line). (b) Northern hemisphere density $\left(\times 10^{-15} \mathrm{~g} \mathrm{~cm}^{-3}\right)$ at $200 \mathrm{~km}$ from the TGCM simulation for 14 UT on September 19, 1984. The satellite track from Figure 10a is superimposed on the dayside.

the storm have increased by $50 \%$ on both the nightside and the dayside. In contrast the densities in the TGCM (not shown) increased by only about $16 \%$. The relatively small increase in the TGCM densities indicates that insufficient energy has been deposited into the TGCM during the simulation.

\section{Discussion}

The final state predicted by any model depends to some extent on the initial state. In the present case, the TGCM was run for several days from a diurnally reproducible 


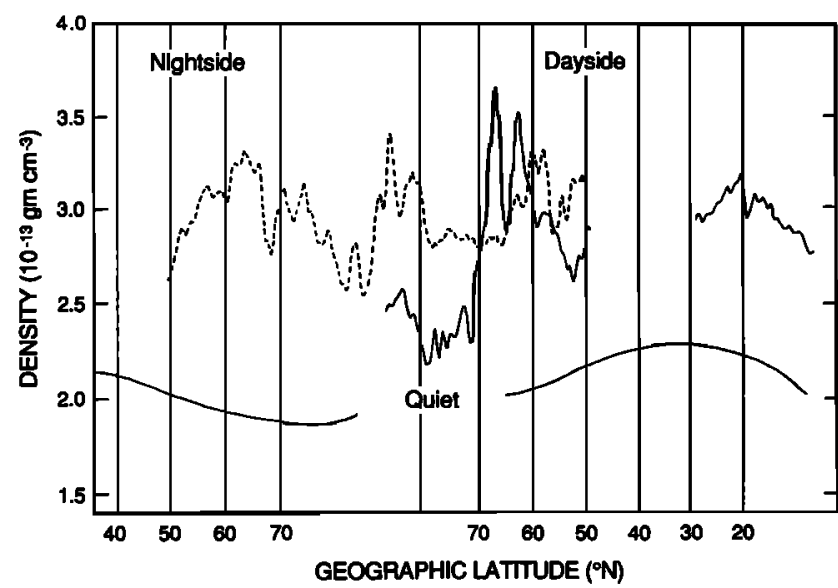

Fig. 11. Latitude variation of neutral density measured close to $200 \mathrm{~km}$ by the S85-1 satellite. Data from passes at 1730 UT (solid line) and 2130 UT (dashed line) on September 19 are compared with the typical corresponding quiet day variation.

equinox solar minimum steady state, using inputs appropriate for a quiet day during September 1984. Since magnetic conditions were quiet for several days preceding the ETS interval and since we have concentrated here on winds, which respond fairly rapidly to changes in the model inputs [Mayr and Hedin, 1977], the initial conditions are not expected to cause serious problems for the present study. This assumption is borne out by the relatively good agreement between the measured and predicted winds and temperatures for the quiet day (September 18) simulation.

In order to assess the validity of the TGCM simulation for the ETS interval, the predicted winds, temperatures, and densities have been compared with those measured during the ETS campaign. In many respects, the agreement between the models and measurements is excellent, but several discrepancies have also emerged from this analysis. The main features will now be discussed.

\subsection{Quiet Day Winds}

The quiet day $F$ region wind variations predicted by the model display a strong semidiurnal variation similar to that observed at many locations, indicating that tidal effects are extremely important and must be modeled correctly if thermospheric predictions are to be realistic. In the present case, the phase of the modeled quiet day wind variation leads the measured phase by $0-4$ hours, and this discrepancy needs to be addressed. The problem is particularly clear in the nighttime equatorward winds, where the largest phase shift seems to be at Rome, while the smallest shift is at the higher magnetic latitude stations: Tomsk and Millstone Hill. A similar problem has been noted for other intervals (e.g., V. B. Wickwar, Global thermospheric studies of neutral dynamics using incoherent scatter radars, submitted to $A d$ vances in Space Research, 1989), which suggests that the problem is significant. The local time variation of the Millstone predictions leads the predicted variation for Rome by about 1 hour. This would be expected because of the clockwise diumal wind rotation and the different magnetic declinations at the two sites (Table 1) if the two wind systems were identical in geographic coordinates. The data reveal that the measured wind variation at Millstone Hill leads the Rome variation by about 4 hours, which is more difficult to explain.

The phase of the thermospheric winds is determined by the interaction of various diurnal and semidiurnal components. The thermospheric diurnal tides are excited almost exclusively in situ [Lindzen, 1970; Lindzen and Blake, 1971] except for the equatorial lower thermosphere. In this study, only in situ diurnal excitation is included. Semidiurnal tidal oscillations are generated by (1) an in situ component due to solar UV and EUV absorption, (2) a propagating component due to the upward moving waves excited by insolation absorption in the lower atmosphere, and (3) diurnal variations in ion drag interacting with diurnal variations in neutral velocities. The in situ excitation and ion-neutral momentum coupling are explicitly included in the model: the propagating semidiurnal components at the lower boundary are parameterized. Verification of the in situ tidal forcing for the ETS interval is beyond the scope of this paper; however, the propagating semidiurnal component at the lower boundary is amenable to investigation and is discussed below.

Since Millstone Hill and Rome have the same geographic latitude, the observed phase anomaly cannot easily be explained purely in terms of upward propagating tides, although Herrero et al. [1983] have qualitatively explained longitudinal differences in tidal behavior by invoking a coupling between the upward propagating tides and the tides generated in situ by both EUV heating and the interaction of the diurnal wind field variations with the diurnal ion density variations. The predicted phase anomaly appears to be fairly insensitive to ion drag, and therefore the background ionosphere in the TGCM. Numerical experiments revealed that increasing the ion drag by $50 \%$ on a global scale produced insignificant changes in the relative phases of the tidal winds predicted for $F$ region altitudes. Since Millstone Hill has a higher magnetic latitude than Rome, differences in the effects of high-latitude forcing at the two sites appear to offer the simplest explanation of the observed phase anomaly.

Recent work by C. G. Fesen (private communication, 1988 ) indicates that the amplitude and phase of the semidiurnal tide obtained in the $F$ region are very sensitive to the degree of high-latitude forcing. High-latitude forcing can generate a pseudotide that interacts with the stable tide from below, and a Fourier decomposition of the disturbed state gives an apparent phase shift in the resultant semidiurnal component. The phase of this component can change by up to 3 hours at mid-latitudes as the cross-polar cap potential drop is increased from zero to $90 \mathrm{kV}$. The amplitude of the apparent semidiurnal tide may correspondingly increase by a factor of 2. The discrepancy between the modeled and observed phases of the $F$ region winds in the present study may well be attributable to inaccurately simulated interactions of this type in the TGCM. High-latitude effects were not considered in the analysis of Fesen et al. [1986], where the equinoctial tide specification was originally deduced. Clearly, the level of geomagnetic activity should be considered in future studies when deriving generic specifications for upward propagating tides by matching $F$ region data with model simulations. Furthermore, the generic tidal specifications deduced from this type of analysis need to be used with caution.

For the ETS simulation the propagating semidiurnal tidal inputs at the lower boundary were those obtained by Fesen et al. [1986] for equinox solar minimum conditions. These 
values were used because the $F_{10.7}$ fluxes observed during September 1984 were comparable with those typical of solar minimum conditions. Fesen et al. [1986] assumed that the antisymmetric modes would be unimportant at the equinox. They obtained amplitudes and phases of the 2,2 and 2, 4 modes as follows: $A(2,2)=600 \mathrm{~m}, A(2,4)=300 \mathrm{~m}, \phi(2$, $2)=-0.5$ hour, $\phi(2,4)=-2.0$ hours. Richmond and Roble [1987] investigated the electrodynamic effects of thermospheric winds from the NCAR TGCM and found that the inclusion of this tidal forcing in the equinoctial TGCM improved the agreement between calculated and observed magnetic variations and electric fields.

Since the higher-order modes tend to be attenuated below $300 \mathrm{~km}, F$ region winds are dominated by the interaction of the in situ tides with the upward propagating $(2,2)$ mode. By way of a numerical experiment we discovered that when the phase of the $(2,2)$ mode is changed at the TGCM lower boundary, the phase of the predicted $F$ region winds changes by a corresponding amount. The incorrect specification of any of the higher tidal modes at the TGCM lower boundary should not necessarily degrade the wind predictions at $F$ region heights, although they clearly influence the quality of the predictions at lower altitudes.

For September 1984, wind data were available from altitudes around $97 \mathrm{~km}$ at four locations. It was therefore possible to compare the semidiurnal tidal amplitudes and phases used at the TGCM lower boundary with the measured monthly mean values. The data for Saskatoon were published by Manson et al. [1986] for Poker Flat by Tetenbaum et al. [1986], and for Kyoto by Vincent et al. [1988]. Adelaide data were generously provided by $R$. A. Vincent (private communication, 1988). Figure 12 summarizes the measured phases and amplitudes of the eastward and northward semidiurnal components. The phase variation with altitude (oblique solid line) was approximately the same for three stations (Saskatoon, Poker Flat, and Adelaide). For Kyoto, data were only published for $90 \mathrm{~km}$, and the altitude variation is assumed to be an average of that observed at the other stations. The measured amplitudes are only indicated at one height for each station since the variation with altitude was generally small.

The phases of the meridional components are essentially the same for all four sites; however, the northern hemisphere zonal components are approximately in antiphase with the Adelaide data. Vincent et al. [1988] found a similar relationship to be present throughout the year when they compared semidiurnal tides from the geographically conjugate locations of Kyoto and Adelaide. They also discovered that the phases exhibit a bimodal character and change rapidly from one state to the other at the equinoxes. The zonal phase for $90 \mathrm{~km}$ at Kyoto changes around September/October from a value of $0700 \mathrm{LT}$ in summer to a value near $0000 \mathrm{LT}$ in winter. The data in Figure 12 thus indicate that the semidiurnal tides during the ETS campaign were in a "northern hemisphere summer" state. Vincent et al. [1988] argue that this type of north-south asymmetry can only be explained by the dominance of antisymmetric modes in the semidiurnal wind oscillations. They invoke the presence of the $(2,3)$ mode in particular, since the $(2,5)$ mode has nulls in the horizontal wind structure function near $35^{\circ} \mathrm{N}$.

Superimposed on Figure 12 are crosses corresponding to the phases and amplitudes of the simulated winds at the TGCM lower boundary. These winds correspond to the upward propagating semidiurnal tides specified according to Fesen et al. [1986]. For the northern hemisphere the measured phase leads the predicted phase by about 1.0-1.5 hours in both components. This represents exceptionally good agreement. However, in the southern hemisphere the measured and predicted winds are approximately in antiphase for both components. The winds at the lower boundary of the TGCM thus fail to reproduce the observed hemispheric asymmetry, and this is probably because the antisymmetric modes were excluded from the TGCM tidal input specification. The phase problem in the $F$ region is more complicated, however. We note that the $F$ region and $97-\mathrm{km}$ phase differences between the TGCM and observed winds in the northern hemisphere have the opposite sign. Thus a simple correction to the total phase at $97 \mathrm{~km}$ would exacerbate the $F$ region problem.

In addition to the phase problem, the amplitudes of the different modes need to be specified. For each site in Figure 12 the amplitude of the TGCM winds at $97 \mathrm{~km}$ exceeds the measured amplitude by factors ranging from $30 \%$ to $200 \%$. Richmond and Roble [1987] have also noted that the semidiurnal tidal amplitudes as specified by Fesen et al. [1986] should be reduced by about $30 \%$. A reduction in the total semidiurnal amplitude at $\mathbf{9 7} \mathrm{km}$ may arise from introducing antisymmetric modes if their phase is appropriate for destructive interference. A detailed analysis of the ETS wind data from altitudes below $100 \mathrm{~km}$ in order to improve the tidal specification at the TGCM lower boundary is outside the scope of this paper. However, this type of analysis may prove very fruitful in the future, particularly if data could be obtained from more sites. The Lower Thermosphere Coupling Study (LTCS), a recent CEDAR campaign, may be able to address this issue.

\subsection{Active Day Winds}

For the storm day the "state of the art" TGCM simulation has predicted many features of the observed winds very well. Particularly noteworthy is the reproduction of the discontinuous wave fronts displayed in Figure 3, following the storm onset. The disturbance also has the correct amplitude and propagation speed, which suggests that the highlatitude inputs are very realistic at this time. However, comparison of the predictions with data has revealed several discrepancies in the model winds: (1) there is no "precursor" event at 06 UT in the American sector, (2) the second part of the observed equatorward wind surge ( $\sim 14 \mathrm{UT})$ is missing, (3) disturbances generated in the southern hemisphere have amplitudes which are too large when they reach the northern hemisphere, and (4) northern hemisphere equatorward winds are too weak later in the storm period, particularly during the nighttime at high latitudes.

The precursor event of September 19 noted in connection with Figure $2 a$ is a departure from the quiet day wind variation at Millstone Hill at $06 \mathrm{UT}$, prior to the onset of the magnetic storm. This disturbance appears to be confined to the high-latitude American sector, including Sondre Stromfjord and Millstone Hill. The $A E$ index plotted in paper 1 indicates that a small substorm commenced about 05 UT on September 19 and peaked at $06 \mathrm{UT}$ with a value of $300 \mathrm{nT}$. Magnetograms for 24 stations throughout the northern hemisphere were available during this interval [Knipp et al., this issue]. They revealed that activity was confined to the 
Poker Flat

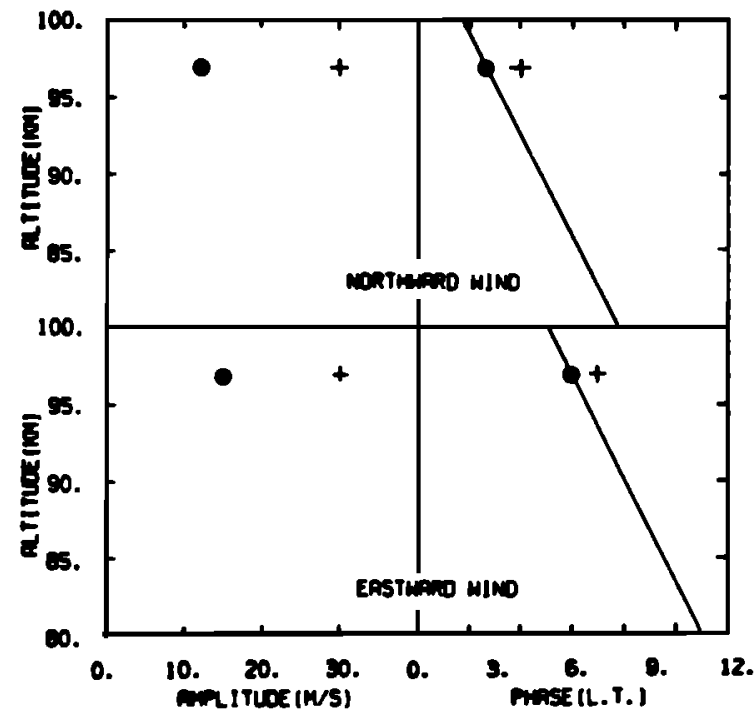

Kyoto

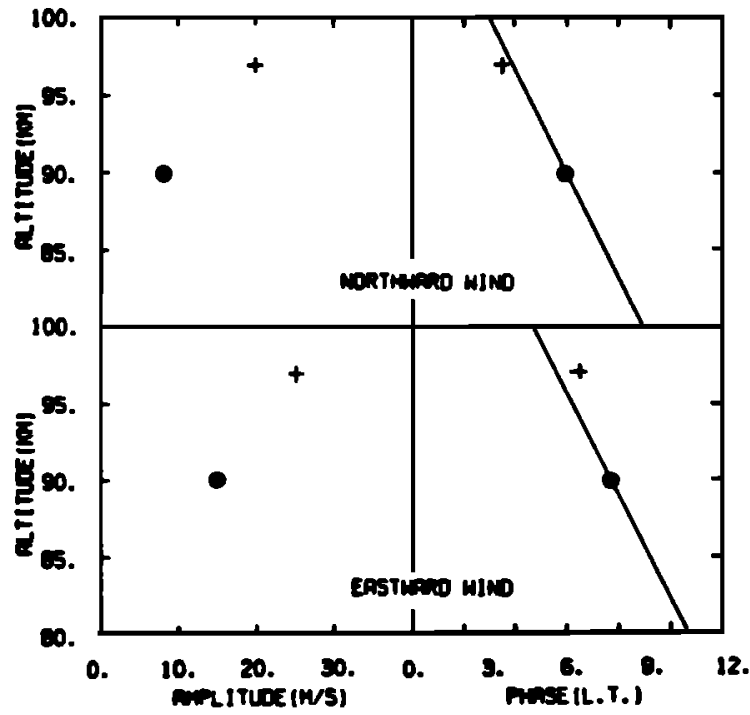

Saskatoon

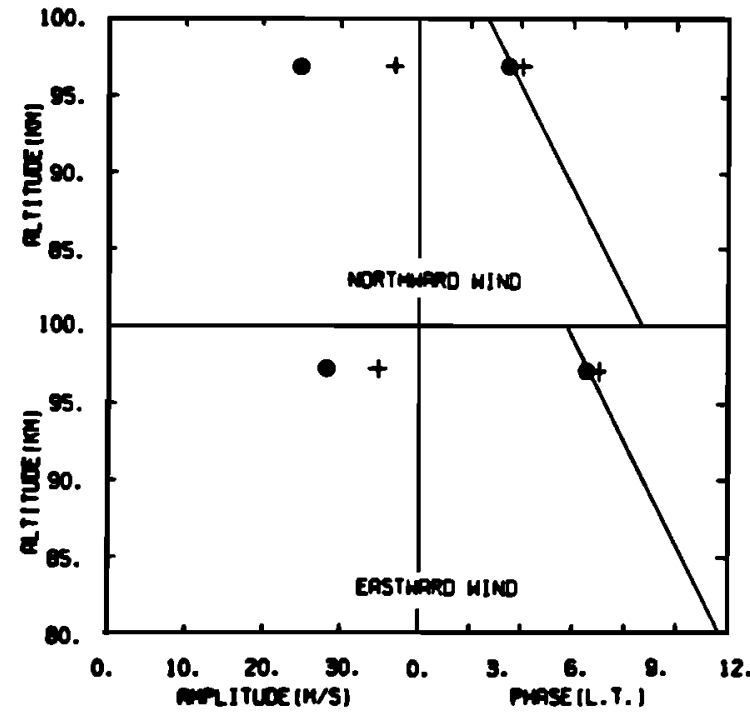

Adelaide

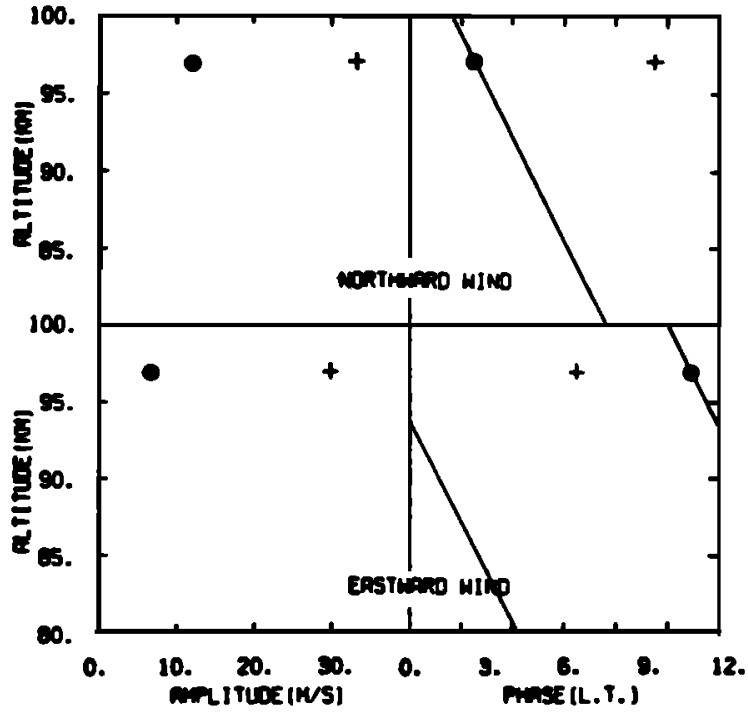

Fig. 12. Monthly mean (September 1984) phase and amplitude variation as a function of altitude for eastward and northward wind components at (a) Poker Flat, (b) Saskatoon, (c) Kyoto, and (d) Adelaide. Oblique lines represent measured phase variation with altitude. Solid circles represent measured values; crosses indicate values in TGCM.

midnight sector, corresponding to longitudes between Greenland and Churchill $\left(50^{\circ}-100^{\circ} \mathrm{W}\right)$. Unfortunately, no magnetograms were available for the immense region between Greenland and Churchill and north of Ottawa $\left(55^{\circ} \mathrm{N}\right.$ magnetic), although the Millstone Hill radar measured electric fields of less than $10 \mathrm{mV} \mathrm{m} \mathrm{m}^{-1}$ up to $65^{\circ} \mathrm{N}$ (magnetic).

The convection patterns used in the TGCM were derived from the AMIE technique and depend on good data coverage for their accuracy. The variations of cross-polar cap potential and Joule heating obtained from the AMIE procedure were described in paper 1 and by Knipp et al. [this issue]. Both parameters have small values at 06 UT. The potentials and $E$ fields obtained from AMIE during this time were underestimated, since the model had essentially no information about the magnetic activity in the critical sector. It is interesting to note that the winds measured at Millstone Hill after 06 UT on September 19 continued to blow equatorward throughout the prestorm period. The reason for this is still not clear, since substorm activity seems to have ceased between 0630 and 0930 UT.

The equatorward wind "surge" observed globally between 10 and 17 UT contained two peaks separated by about 2 hours and will be discussed in more detail in a later paper. The nature of this surge is not clear, and the two current working hypotheses regard the surge either as two cycles of a single periodic wave or as two distinct events each having a single cycle. The surge generated in the TGCM simulation corresponded to the first of the observed peaks. The source of the disturbance in the TGCM was a region of intense Joule heating over Alaska and western Canada in the postmidnight sector at about $10 \mathrm{UT}$. This was approximately the time at which the $A E$ index increased dramatically by $1000 \mathrm{nT}$ 
because of the storm onset. The origin of a second observed disturbance might be expected to be in a similar location to the source of the first event (since many of the properties of the two disturbances are similar) except 2 hours later (i.e., about $12 \mathrm{UT}$ ); however, there is no evidence of such a source in the high-latitude data. The $A E$ index is generally decreasing from $11 \mathrm{UT}$. At $12 \mathrm{UT}$ there is a short-lived enhancement from 800 to $10 \mathrm{nT}$, but it seems unlikely that such an event could launch a disturbance of the same magnitude as the $10 \mathrm{UT}$ storm onset. This evidence indicates that the second peak may be the second cycle of a single large-scale gravity wave having a period of about 2 hours. The second cycle of the $F$ region wind variation was not predicted by the TGCM, and theory predicts that dissipation should restrict the observed mid-latitude response to a single pulse [Testud, 1973; Richmond, 1978]. However, the TGCM density predictions from lower altitudes did contain a propagating disturbance at 14 UT (Figure 10), and it is not clear at the moment either why there was no corresponding $F$ region wind effect or what was the source of the disturbance.

Wavelike disturbances have rarely been observed on the global scale. A recent example from the Worldwide Atmospheric Gravity Wave Study (WAGS) campaign was described by Rice et al. [1988], who deduced the most likely origin of their wave to be in the evening sector of the auroral oval. Identification of the source characteristics is a primary goal of gravity wave research. Further analysis of the TGCM for the ETS period promises to reveal important information regarding the source of the propagating disturbance(s) described here.

Ionosonde data from the southern hemisphere indicate that a large-amplitude disturbance was also generated at southern high latitudes in association with the storm onset about 10 UT. The TGCM predicted a large-scale disturbance launched in the southern hemisphere about 10 UT which propagated equatorward. The amplitude of the model disturbance was largest in the Australian sector $\left(\sim 150^{\circ} \mathrm{E}\right)$, although it had only half the amplitude of the corresponding disturbance in the northern hemisphere. Both disturbances crossed the equator at about the same time (14 UT) and propagated into the opposite hemisphere. The disturbance from the southern hemisphere reached Tokyo at $16 \mathrm{UT}$, causing a rapid reversal from equatorward to poleward winds (Figure $2 e$ ) in the TGCM predictions. A similar problem was encountered in the European sector about 22 UT (Figure $2 c$ ) due to a southern hemisphere disturbance launched at $18 \mathrm{UT}$ in association with the third major substorm onset of the day. These disturbances from the southern hemisphere thus contribute to the discrepancy between the predicted and measured winds in the northern hemisphere.

As explained in paper 1 , the lack of southern hemisphere high-latitude data precludes the direct determination of potential patterns using the AMIE technique. Furthermore, the AMIE potentials obtained from the northern hemisphere cannot be used directly in the southern hemisphere. As an interim measure, the southern hemisphere convection pattern was approximated by the Heelis model appropriately tuned by means of the northern hemisphere AMIE potentials. The integrated Joule heating and momentum forcing in the southern hemisphere is thus expected to be of the correct order of magnitude; however, the TGCM is not expected to reproduce details of the energy and momentum inputs.
Therefore further analysis of the waves emanating from the southern hemisphere is not deemed worthwhile at this time. However, the existence of these waves indicates that the southern hemisphere cannot be ignored in the future if realistic global simulations are to be achieved.

In addition to the equatorward wind surge in the early part of the storm interval, unusually strong equatorward winds were also observed in the late storm period 16-23 UT at many mid- to high-latitude stations. In general, these winds were underestimated by the TGCM, particularly for the nightside. The techniques by which meridional winds are estimated from radar and ionosonde data make several assumptions which are likely to be inappropriate during magnetically active intervals, particularly at high latitudes. It seems unlikely, however, that the assumptions could account entirely for the discrepancy, which often amounts to more than $100 \mathrm{~m} \mathrm{~s}^{-1}$ for individual stations (Figure $6 b$ ). The TGCM was therefore examined for causes of underestimated equatorward winds.

Meridional winds in the nighttime sector can be generated by both momentum and heat sources. Killeen and Roble [1984, 1986] demonstrated that the $F$ region winds are controlled by the balance between ion drag and pressure forces, and the midnight surge is caused by acceleration of air parcels over the polar cap by momentum forcing. During the entire ETS storm interval of September 19, antisunward winds in the polar cap exceeded $500 \mathrm{~m} \mathrm{~s}^{-1}$ in the TGCM, spilling out into the nightside sector at lower latitudes and with reduced speeds. Various high-latitude heat sources also contributed to these winds by means of pressure gradients directed from high to low latitudes.

Between 18 and 22 UT the EISCAT radar was in the late evening sector and measured the antisunward winds flowing out of the polar cap. The observed meridional wind speed ranged from 300 to $400 \mathrm{~m} \mathrm{~s}^{-1}$ while the TGCM predicted speeds of only $150-200 \mathrm{~m} \mathrm{~s}^{-1}$. This comparison suggests that the momentum forcing in the polar cap is not accurately specified in the TGCM. Both the electric fields and the electron concentration contribute directly to the momentum forcing, and both involve a large degree of uncertainty. The polar cap potentials from the AMIE technique are uncertain because of the lack of polar cap electrodynamic data, and in future work of this nature, polar cap drifts such as those measured by digital ionosondes [e.g., Reinisch et al., 1987] should be included in the AMIE analysis. The electron concentration in the TGCM is specified by the IRI model together with cusp, polar rain, and auroral precipitation. In the future, the NCAR thermosphere/ionosphere general circulation model (TIGCM) of Roble et al. [1988a] will be employed, which includes an interactive ionosphere. One of the features of the interactive ionosphere is the generation of enhanced polar cap electron concentrations [e.g., FullerRowell et al., 1987], which leads to the possibility of stronger forcing of the neutral winds as they are accelerated across the polar cap.

It is difficult to explain the weak equatorward winds entirely in terms of momentum forcing. The weak latitudinal temperature gradients and small density increases in the TGCM also suggest that additional high-latitude heating is required. The additional heating may be supplied by Joule heating, particle heating, plasma heating from wave-particle interactions, or enhanced magnetospheric heat flows. The Joule heating already in the model seems likely to be 
reasonably accurate since the auroral convection and $E$ region precipitation have been tuned by reference to measured quantities. Smith et al. [1982] showed that moderate fluxes of soft $(\sim 200 \mathrm{eV})$ particles at high latitudes could generate significant equatorward winds at mid-latitudes. Since the only form of soft particles in the TGCM is currently the cusp and drizzle precipitation [Roble and Ridley, 1987], there is good reason to place additional soft particle precipitation in the auroral zone. In addition to stronger equatorward winds, such a source would also generate increased latitudinal temperature gradients in the $F$ region, and particles deposited at $150-180 \mathrm{~km}$ would produce additional neutral density enhancements at $200 \mathrm{~km}$. Undetected soft particle precipitation to the north of Millstone Hill may also explain the "precursor event" at 06 UT noted in Figure $2 a$.

\section{Summary and Conclusions}

This is the third in a series of time-dependent simulations for specific intervals [cf. Roble et al., 1987, 1988b]. In previous studies, the high-latitude TGCM inputs have been parameterized in a semiempirical fashion, which has led to a type of quasi-averaged result. The TGCM inputs in the present case represent the current "state of the art." The high-latitude inputs have been tuned so that they more closely resemble measured quantities such as auroral particle precipitation and high-latitude electric fields. The data have enabled the convection pattern and auroral oval to be defined with unprecedented precision for this simulation; however, the dynamic and nonuniform nature of the auroral oval and convection pattern means that they cannot be defined exactly with the present limited data set. Tuning of the high-latitude inputs was very labor intensive, although the process has now been developed to a semiautomatic level. Upward propagating semidiurnal tides have also been included in the model, according to the specifications of Fesen et al. [1986].

The model predictions for September 18-19, 1984, have been compared with global observations of the meridional neutral wind in addition to neutral temperature and density measurements on a more limited scale. In many respects, the agreement between the predictions and observations is generally good, although various discrepancies remain. Highlights include the following:

1. The strong semidiurnal quiet day $F$ region wind variation is reproduced by the model and emphasizes the importance of tidal effects for the dynamics of the upper thermosphere.

2. The storm day equatorward wind surge with its distorted and discontinuous fronts is reproduced with the correct amplitude and propagation speed. The timing of the event is correct to within $15 \mathrm{~min}$.

3. A four-cell high-latitude neutral density anomaly has been discovered. Corresponding features were measured by satellite at $200 \mathrm{~km}$ altitude.

4. Enhanced temperatures were measured at high latitudes following the storm onset. Similar enhancements were predicted by the TGCM, permitting the cause of the temperature increase to be investigated.

For the first time the differences between the predicted and measured winds have been quantitatively assessed on a statistical basis. The differences tend to be largest during the night at high latitudes following a magnetic storm. The smallest differences occur during the daytime at low latitudes, particularly for magnetically quiet conditions. In the present study, the best agreement between the predicted and measured winds was found for Arecibo.

Exact replication of measured thermospheric conditions by the TGCM should not be expected, even assuming all the important processes are included in the model, since the initial conditions and many details of the thermospheric forcing are not accurately known. The wind measurements should also be treated with caution since they involve several assumptions which are likely to be inappropriate during magnetically active conditions, particularly at high latitudes.

Several discrepancies between the predicted and observed winds were discussed in detail:

1. The quiet day semidiurnal variation of the $F$ region winds is dominated by the upward propagating $(2,2)$ mode. An anomalous phase relationship between the winds observed at different locations is not reproduced by the model, suggesting that interactions between the tides and the highlatitude forcing are important and require further study.

2. On the active day a precursor event observed in the American sector was not predicted, because of the lack of input data.

3. The nature of the equatorward wind surge observed at Millstone Hill and Arecibo following the storm onset is still not fully understood. Detailed analysis of the wind variation has revealed two maxima separated by 2 hours; however, there is no strong evidence for a source capable of generating a second disturbance 2 hours after the first event. This suggests that the surge may be a single wave with two cycles. The second peak was not predicted by the model, and this discrepancy is not understood.

4. Throughout the storm period the measured equatorward winds were stronger than the predicted winds. One reason for this may be insufficient momentum forcing at high latitudes due to inappropriate polar cap convection and electron concentrations. A second reason was the influence of poleward winds associated with waves propagating from the southern hemisphere. Since very few data were available to define the high-latitude inputs, the southern hemisphere was not discussed in detail. This study indicates that the southern hemisphere cannot be ignored if the northern hemisphere thermosphere is ever to be fully understood.

5. Both the observed temperature gradients and storm time density enhancements indicate that insufficient highlatitude heating is being applied to the model. This is quantitatively consistent with the lack of equatorward winds in the model. We have suggested that the TGCM requires an additional source of high-latitude heat in the form of soft $(<200 \mathrm{eV})$ particle precipitation, but the influence of other high-altitude plasma heat sources cannot be discounted.

6. Wind data from altitudes below $100 \mathrm{~km}$ revealed shortcomings of the generic equinox solar minimum tidal specification used in the TGCM. Contrary to the usual assumptions, the asymmetric modes are still important at equinox. In the future, wind data from altitudes below 100 $\mathrm{km}$ should be used to improve the TGCM tidal inputs for specific campaign intervals.

Eventually, the TGCM will be used as an operational predictive model. The present study reveals the type of input information which will be necessary to make realistic fore- 
casts of thermospheric behavior. For magnetically quiet intervals at low latitudes the solar and tidal forcing terms are dominant, and the definition of high-latitude TGCM inputs is relatively unimportant. The tidal inputs were discussed in detail above, and several problems were identified. The solar EUV/UV fluxes are also largely unknown. They are parameterized in the TGCM by means of the daily $\boldsymbol{F}_{10.7}$ flux but in practice are highly variable and not currently measured.

To obtain accurate thermospheric forecasts for high latitudes and for geomagnetically active conditions, a knowledge of the high-latitude forcing terms is vital. Of particular importance are the convection pattern and auroral particle precipitation. The results discussed above indicate that the accurate specification of large-scale features of the auroral oval such as location, size, and particle energies is feasible using a simple model with small quantities of data. At this stage, the relative importance of smaller-scale features such as discrete auroral arcs is not known. The high-latitude convection pattern seems to be a less tractable problem. This difficulty with the convection pattern is presumably a reflection of the complexity of the convection as compared with the auroral oval. Simultaneous measurement of the entire convection pattern has to be a high priority in the future. The conductances in the TGCM are different from those used by the AMIE technique and are not therefore electrically consistent with the potential pattern from AMIE. Future objectives should include electrodynamic coupling between the potential patterns and conductances in the TGCM.

Development of the TGCM is continuing. Roble et al. [1988a] have recently described a new version of the model (TIGCM) which includes a fully interactive ionosphere and additional high-latitude heating due to soft particle fluxes. The aeronomical scheme in the TIGCM is also revised and includes radiative cooling at $5 \mu \mathrm{m}$ due to $\mathrm{NO}$, in addition to the $15-\mu \mathrm{m} \mathrm{CO}$ cooling. The lack of an interactive ionosphere has been considered as a possible contributor to the differences between model predictions and measurements in the present study. With an interactive ionosphere the convection of dayside $F$ region plasma over the polar cap would produce higher polar cap electron concentrations than the IRI model. The forcing of cross-polar cap winds may therefore be enhanced in an interactive model. The interactive ionosphere would not significantly affect the tidal wind phases.

Owing to the known shortcomings of the current TGCM, the composition and densities have not been discussed in depth in the present paper. Moreover, the only composition estimates available for day $\mathbf{2 6 2}$ are those from the Millstone Hill radar. These will be discussed at a later stage, when the new TIGCM is fully operational.

This study demonstrates the value of coordinated global campaigns, especially those which last for several days. Direct measurements of the thermospheric neutral winds from Fabry-Perot interferometers (FPI) would generally complement the data from other instruments; however, no suitable FPI data were obtained during the ETS campaign. Estimates of the meridional neutral wind obtained from $h_{\max } F_{2}$ measured by ionosondes are also particularly useful in extending the network of wind observations. Although a large number $(>50)$ of ionosondes are currently operational worldwide, estimates of $h_{\max } F_{2}$, or the parameters (e.g., $M(3000) F_{2}$ ) from which it may be calculated, are not rou- tinely available from most stations. If hourly values of $h_{\max } F_{2}$ could be obtained during the coordinated campaigns, the value of ionospheric soundings would be greatly enhanced, and the data would play an important role in improving our understanding of the thermosphere.

Acknowledgments. This research effort was supported in part by the NASA Solar-Terrestrial Theory Program (NASA contract W-16, 320) and the Air Force Office of Scientific Research task 2310G9 (with the Air Force Geophysics Laboratory). The research programs at Millstone Hill/Haystack Observatory, Arecibo Observatory, SRI International, and CASS were supported by the NSF Upper Atmosphere Facilities and Aeronomy Programs. V. B. Wickwar was employed by SRI International during the early stages of this study. We are grateful to Cassandra Fesen and Maura Hagan for helpful discussions concerning thermospheric tides and thermospheric temperatures, respectively. We gratefully acknowledge Bob Vincent, who generously supplied tidal data from Adelaide (Figure 12). We also acknowledge Ian McCrea (Leicester University, England) who provided EISCAT data and Lisa Shier (HAO) who computed meridional neutral winds from the EISCAT data.

The Editor thanks H. G. Mayr and R. W. Smith for their assistance in evaluating this paper.

\section{REFERENCES}

Bilitza, D., International reference ionosphere: Recent developments, Radio Sci., 21, 343-346, 1986.

Buonsanto, M., J. E. Salah, K. L. Miller, W. L. Oliver, R. G. Burnside, and P. G. Richards, Observations of neutral circulation at mid-latitudes during the Equinox Transition Study, J. Geophys. Res., this issue.

Burnside, R. G., C. A. Tepley, and V. B. Wickwar, The $\mathrm{O}^{+}-\mathrm{O}$ collision cross-section: Can it be inferred from aeronomical measurements?, Ann. Geophys., 5, 343-350, 1987.

Burnside, R. G., M. P. Sulzer, and J. C. G. Walker, Determination of thermospheric temperatures and neutral densities at Arecibo from the ion energy balance, J. Geophys. Res., 93, 8642-8650, 1988.

Carlson, H. C., Jr., and G. Crowley, The Equinox Transition Study: An overview, J. Geophys. Res., this issue.

Crowley, G., B. A. Emery, R. G. Roble, H. C. Carlson, Jr., and D. J. Knipp, Thermospheric dynamics during September 18-19, 1984, 1, Model simulations, J. Geophys. Res., this issue.

Fesen, C. G., R. E. Dickinson, and R. G. Roble, Simulation of thermospheric tides at equinox with the NCAR thermospheric general circulation model, J. Geophys. Res., 91, 4471-4489, 1986.

Fuller-Rowell, T. J., D. Rees, S. Quegan, R. J. Moffett, and G. J. Bailey, Interactions between neutral thermospheric composition and the polar ionosphere using a coupled thermosphereionosphere model, J. Geophys. Res., 92, 7744-7748, 1987.

Hagan, M. E., Effects of geomagnetic activity in the winter thermosphere, 2, Magnetically disturbed conditions, J. Geophys. Res., 93, 9937-9944, 1988.

Hagan, M. E., and J. E. Salah, Effects of geomagnetic activity in the winter thermosphere, 1, Magnetically undisturbed conditions, $J$. Geophys. Res., 93, 9927-9935, 1988.

Harper, R. M., Nighttime meridional winds near $350 \mathrm{~km}$ at low to mid latitudes, J. Atmos. Terr. Phys., 35, 2023-2034, 1973.

Hedin, A. E., A revised thermospheric model based on mass spectrometer and incoherent scatter data: MSIS-83, J. Geophys. Res., 88, 10,170-10,188, 1983.

Hedin, A. E., MSIS-86 thermospheric model, J. Geophys. Res., 92, 4649-4662, 1987.

Herrero, F. A., H. G. Mayr, and N. W. Spencer, Latitudinal (seasonal) variations in the thermospheric midnight temperature maximum: A tidal analysis, J. Geophys. Res., 88, 7225-7235, 1983.

Killeen, T. L., and R. G. Roble, An analysis of the high-latitude thermospheric wind pattern calculated by a thermospheric general circulation model, 1, Momentum forcing, J. Geophys. Res., 89, 7509-7522, 1984.

Killeen, T. L., and R. G. Roble, An analysis of the high-latitude thermospheric wind pattern calculated by a thermospheric general 
circulation model, 2, Neutral parcel transport, J. Geophys. Res., 91, 11,291-11,307, 1986.

Knipp, D. J., et al., Electrodynamic patterns for September 19, 1984, J. Geophys. Res., this issue.

Lindzen, R. S., Internal gravity waves in atmospheres with realistic dissipation and temperature, 1, Mathematical development and propagation of waves into the thermosphere, Geophys. Astrophys. Fluid Dyn., 1, 303-355, 1970.

Lindzen, R. S., and D. W. Blake, Internal gravity waves in atmospheres with realistic dissipation and temperature, II, Thermal tides excited below the mesopause, Geophys. Astrophys. Fluid Dyn., 3, 31-61, 1971.

Manson, A. H., C. E. Meek, S. K. Avery, and D. Tetenbaum, Comparison of mean wind and tidal fields at Saskatoon $\left(52^{\circ} \mathrm{N}\right.$, $\left.107^{\circ} \mathrm{W}\right)$ and Poker Flat $\left(65^{\circ} \mathrm{N}, 147^{\circ} \mathrm{W}\right)$ during $1983 / 1984$, Rep. 5 , Univ. of Sask., Saskatoon, Canada, 1986.

Marcos, F. A., and J. M. Forbes, Thermospheric winds from the satellite electrostatic triaxial accelerometer system, $J$. Geophys. Res., 90, 6543-6552, 1985.

Mayr, H. G., and A. E. Hedin, Significance of large-scale circulation in magnetic storm characteristics with application to AE-C neutral composition data, J. Geophys. Res., 82, 1227-1234, 1977.

Miller, K. L., D. G. Torr, and P. G. Richards, Meridional winds in the thermosphere derived from measurement of $F_{2}$ layer height, J. Geophys. Res., 91, 4531-4535, 1986.

Miller, K. L., J. E. Salah, and D. G. Torr, The effect of electric fields on measurements of meridional neutral winds in the thermosphere, Ann. Geophys., Ser. A, 5, 337-342, 1987.

Oliver, W. L., and J. E. Salah, The global thermospheric mapping study, J. Geophys. Res., 93, 4039-4059, 1988.

Reinisch, B. W., J. Buchau, and E. Weber, Digital ionosonde observations of the polar cap $F$-region convection, Phys. Scr., 36, 372-377, 1987.

Rice, D. D., R. D. Hunsucker, L. J. Lanzerotti, G. Crowley, P. J. S. Williams, J. D. Craven, and L. Frank, An observation of atmospheric gravity wave cause and effect during the October 1985 WAGS campaign, Radio Sci, , 23, 919-930, 1988.

Richmond, A. D., Gravity wave generation, propagation, and dissipation in the thermosphere, J. Geophys. Res., 83, 4131-4145, 1978.

Richmond, A. D., and Y. Kamide, Mapping electrodynamic features of the high-latitude ionosphere from localized observations: Technique, J. Geophys. Res., 93, 5741-5759, 1988.

Richmond, A. D., and R. G. Roble, Electrodynamic effects of thermospheric winds from the NCAR thermospheric general circulation model, J. Geophys. Res., 92, 12,365-12,376, 1987.

Rishbeth, H., Thermospheric winds and the $F$-region: A review, $J$. Atmos. Terr. Phys., 34, 1-47, 1972.

Roble, R. G., and E. C. Ridley, An auroral model for the NCAR thermospheric general circulation model (TGCM), Ann. Geophys., Ser. A, 5(6), 369-382, 1987.

Roble, R. G., J. M. Forbes, and F. A. Marcos, Thermospheric dynamics during the March 22, 1979, magnetic storm, 1, Model simulations, J. Geophys. Res., 92, 6045-6068, 1987.

Roble, R. G., E. C. Ridley, A. D. Richmond, and R. E. Dickinson, A coupled thermosphere/ionosphere general circulation model, Geophys. Res. Lett., 15, 1325-1328, 1988a.

Roble, R. G., T. L. Killeen, N. W. Spencer, R. A. Heelis, P. H. Reiff, and J. D. Winningham, Thermospheric dynamics during November 21-22, 1981: Dynamics Explorer measurements and thermospheric general circulation model predictions, J. Geophys. Res., 93, 209-245, 1988b.

Salah, J. E., and J. M. Holt, Midlatitude thermospheric winds from incoherent scatter radar and theory, Radio Sci., 9, 301-313, 1974.

Schunk, R. W., and J. C. G. Walker, Theoretical ion densities in the lower ionosphere, Planet. Space Sci., 21, 1875-1896, 1973.

Smith, M. F., D. Rees, and T. J. Fuller-Rowell, The consequences of high latitude particle precipitation on global thermospheric dynamics, Planet. Space Sci., 30, 1259-1267, 1982.

Tepley, C. A., and R. B. Kerr, Temporal, seasonal, and solar cycle variations of the topside proton concentration at Arecibo, $A d v$. Space Res., 7, 291-294, 1987.

Testud, J., Ondes atmosphériques de grande échelle et sous-orages magnétiques, Ph.D. thesis, Univ. of Paris VI, Paris, 1973.

Tetenbaum, D., S. K. Avery, and A. C. Riddle, Observations of mean winds and tides in the upper mesosphere during 1980-1984, using the Poker Flat, Alaska, MST radar as a meteor radar, $J$. Geophys. Res., 91, 14,539-14,555, 1986.

Vasseur, G., Vents dans la thermosphère déduits des mesures par diffusion de Thomson, Ann. Geophys., 25, 517-524, 1969.

Vincent, R. A., T. Tsuda, and S. Kato, A comparative study of mesospheric solar tides observed at Adelaide and Kyoto, $J$. Geophys. Res., 93, 699-708, 1988.

R. G. Burnside, Arecibo Observatory, P.O. Box 995, Arecibo, PR 00613 .

H. C. Carlson, Jr., and F. A. Marcos, Air Force Geophysics Laboratory, Hanscom Air Force Base, Bedford, MA 01731.

G. Crowley, Center for Atmospheric Research, University of Lowell, 450 Aiken Street, Lowell, MA 01854.

B. A. Emery and R. G. Roble, High Altitude Laboratory, National Center for Atmospheric Research, P.O. Box 3000, Boulder. CO 80307.

K. L. Miller and V. B. Wickwar, Center for Atmospheric and Space Sciences, Utah State University, Logan, UT 84322.

W. E. Oliver, Department of Electrical, Computer and Systems Engineering, Boston University, 44 Cummington Street, Boston, MA 02215.

J. E. Salah, Haystack Observatory, Massachusetts Institute of Technology, Westford, MA 01886.

(Received March 13, 1989;

revised July 17, 1989;

accepted July $18,1989$. 